\title{
Self-organized criticality theory and the expansion of PD-1-positive effector CD4 T cells: search for autoantibody- inducing CD4 T cells
}

\author{
Yumi Miyazaki ${ }^{1}$, Ken Tsumiyama ${ }^{1}$, Takashi Yamane ${ }^{2}$, Mitsuhiro Ito $^{3}$ and Shunichi Shiozawa ${ }^{1,4 *}$ \\ Department of Medicine, Kyushu University Beppu Hospital, Beppu, Japan \\ 2 Rheumatic Diseases Center, Konan Kakogawa Hospital, Kakogawa, Japan \\ ${ }^{3}$ Department of Biophysics, Graduate School of Health Sciences, Kobe University, Kobe, Japan \\ ${ }^{4}$ Global Center of Excellence, Japan \\ ${ }^{*}$ Correspondence: shiozawa@beppu.kyushu-u.ac.jp \\ Edited by: \\ Takashi Saito, Research Center for Allergy and Immunology, Japan \\ Reviewed by: \\ Takashi Saito, Research Center for Allergy and Immunology, Japan
}

\section{SELF-ORGANIZED CRITICALITY THEORY AND THE CAUSE OF SLE}

The cause of systemic lupus erythematosus (SLE) remains unknown (Fu et al., 2011; Perry et al., 2011). A critical question in elucidating the pathogenesis of SLE or autoimmunity would be how autoreactive clones emerge and expand in the host. According to the prevailing view of autoimmune disease, autoreactive clones may come from either clones that had escaped negative selection in the thymus or clones that have been reactivated from tolerance. However, clones that would emerge by either process would be restricted in their antigen specificity and apparently could not account for the broad T cell receptor (TCR) repertoire and the more than 100 distinct autoantibody specificities found in SLE (Shiozawa, 2012).

We have subsequently developed an alternative novel theory, called the selforganized criticality theory, which proposes that autoreactive lymphocyte clones are newly generated via de novo TCR revision from non-autoreactive clones at peripheral lymphoid organs (Tsumiyama et al., 2009). We identified a CD4 T cell subset that has passed through TCR $\alpha$ but not TCR $\beta$ revision at peripheral lymphoid organ spleen, and we named this an "autoantibodyinducing CD4 T cell” (aiCD4 T cell).

The term "self-organized criticality" is derived from systems engineering. The theory proposes that systemic autoimmunity or SLE, necessarily takes place when the host's immune system is overdriven by repeated exposure to antigen, reaching levels that surpass the immune system's stability-limit, i.e., self-organized criticality
(Tsumiyama et al., 2009; Shiozawa, 2011, 2012). In our experiments, the novel $T$ cells that result from such overstimulation, i.e., aiCD4 T cells, not only could induce B cells to generate a large variety of autoantibodies, but also promote final differentiation of CD8 T cells into cytotoxic T lymphocytes (CTL) via antigen cross-presentation, leading to the tissue injuries identical to those seen in SLE (Tsumiyama et al., 2009). Thus, this aiCD4 $\mathrm{T}$ cell is functionally indispensable for the pathogenesis of SLE. However, a precise characterization of these cells is still in progress, and we report here our recent findings on the distinct cell surface markers that characterize and identify ai $\mathrm{CD} 4 \mathrm{~T}$ cells.

\section{THE aiCD4 T CELL AND PD-1-P0SITIVE EFFECTOR CD4 T CELL}

To further characterize the surface marker of aiCD4 T cell, we generated aiCD4 T cells in BALB/c mice, a strain that is normally not prone to autoimmune disease: 8 -week-old $\mathrm{BALB} / \mathrm{c}$ mice were repeatedly immunized (12×) with $100 \mu \mathrm{g}$ KLH (Sigma, St. Louis, MO, USA), $500 \mu$ g OVA (grade V; Sigma), $25 \mu \mathrm{g}$ SEB (Toxin Technologies, Sarasota, FL, USA), or PBS by means of i.p. injection every 5 days. This protocol has been previously found to generate aiCD4 T cells capable of inducing a variety of autoantibodies and pathological lesions identical to those seen in SLE (Tsumiyama et al., 2009). We found a significant expansion of CD4 $T$ cells that expressed the PD- $1^{\text {high }}$ marker (Figure 1A). These PD- $1^{\text {high }} \mathrm{CD} 4 \mathrm{~T}$ cells further expressed $\mathrm{CD} 44^{\text {high }} \mathrm{CD} 62 \mathrm{~L}^{\text {low }}$ effector $\mathrm{T}$ cell markers, but not $\mathrm{CD} 44^{\text {high }} \mathrm{CD} 62 \mathrm{~L}^{\text {high }}$ memory $\mathrm{T}$ cell markers (Figure 1B). In addition, these cells expressed CD27 $7^{\text {low }}$ CD45RB ${ }^{\text {low }}$, and $\mathrm{CD} 122^{\text {high }}$ markers (Miyazaki et al., 2013). We found that transfer of these PD-1-positive effector $\mathrm{CD} 4 \mathrm{~T}$ cells into naïve recipients induced the generation of rheumatoid factor (RF) and anti-dsDNA antibodies. RF levels in the recipients were $39.36 \pm 10.92 \mathrm{U} / \mathrm{ml}(n=3)$ vs. $11.38 \pm 5.21 \mathrm{U} / \mathrm{ml}(n=7)$ in the controls $(P<0.0005)$, while anti-dsDNA antibody was $0.43 \pm 0.02 \mathrm{AU}(n=3)$ vs. $0.25 \pm 0.03 \mathrm{AU}$ $(n=7)(P<0.01)$, respectively.

Upon encounter with antigen, naïve CD4 T cells normally mature into CD27 $7^{\text {low }}$, CD127 $7^{\text {low }}, \mathrm{CCR} 7^{\text {low }}, \mathrm{CD} 44^{\text {high }} \mathrm{CD} 62 \mathrm{~L}^{\text {low }}$ effector cells (McKinstry et al., 2007; Wang et al., 2007). These effector cells subsequently differentiate into memory cells accompanied by increased expression of CD27, CD62L, CD127, and finally of PD-1 (Duraiswamy et al., 2011).

PD-1 belongs to the CD28 superfamily and is expressed on regulatory $\mathrm{T}$ cells (Treg) (Francisco et al., 2009), T follicular helper (Tfh) cells (Haynes et al., 2007), memory T cells, and exhausted CD8 T cells (Duraiswamy et al., 2011; Jin et al., 2011). PD-1 conveys a negative signal that causes reduced production of $\mathrm{T}$ cell cytokines, including IFN $\gamma$, TNF $\alpha$, and IL-2 (Riella et al., 2012), and induces $\mathrm{T}$ cell tolerance (Jin et al., 2011; Riella et al., 2012).

We, however, saw no increase in FoxP $3^{+} \mathrm{CD} 25^{+}$Treg upon repeated immunization with antigen in $\mathrm{BALB} / \mathrm{c}$ mice. While $\mathrm{CD} 25^{-} \mathrm{CD} 4 \mathrm{~T}$ cells were increased in OVA-immunized mice as compared to PBS-treated mice; 80.1 vs. $68.3 \%(P<0.01)$, the signal ratio of gene expression under 


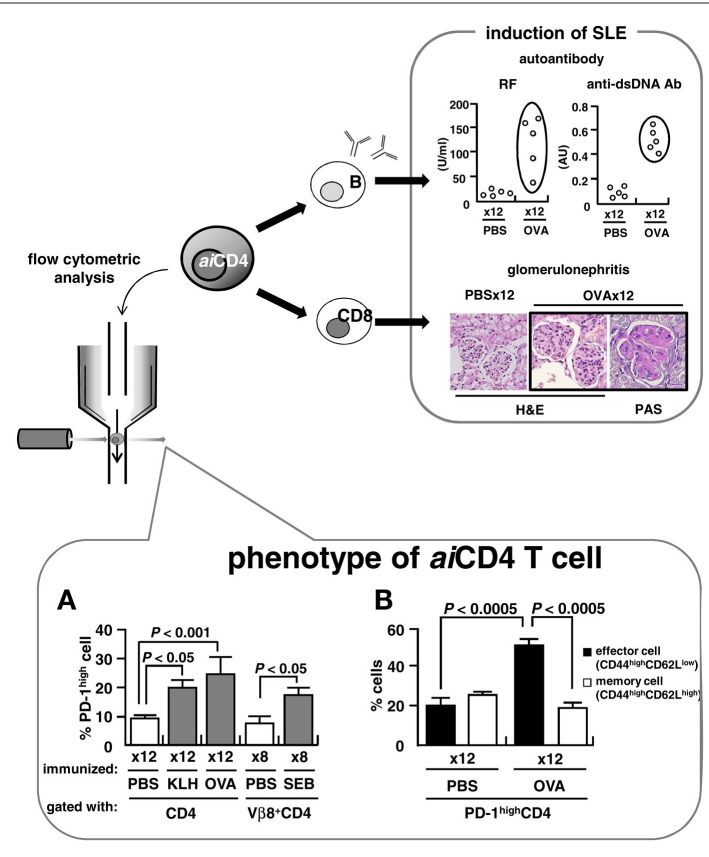

FIGURE 1 | Pathogenesis of SLE and aiCD4T cell. BALB/c mice were repeatedly injected i.p. with $100 \mu \mathrm{g}$ of keyhole limpet hemocyanin (KLH), $500 \mu \mathrm{g}$ of OVA, $25 \mu \mathrm{g}$ of staphylococcal enterotoxin B (SEB), or PBS every 5 days. Adjuvants were not used. (A,B) Flow cytometry analyses of CD4T cells following 12x repeated immunization with antigens (lower). Cells were stained on ice in the dark for 30 min with PerCP Cy5.5-conjugated anti-CD4 antibody (RM4-5), APC-conjugated anti-CD62L antibody (MEL-14), PEconjugated anti-PD-1 antibody (J43) and anti-VB8TCR antibody (F23.1), or FITC-conjugated anti-CD44 antibody (IM7). Samples were analyzed using a BD PharMingen FACSCalibur instrument. Effector and memory functions of PD- $1^{\text {high }}$ CD4T cells were determined by expression of CD44 ${ }^{\text {high }}$ CD62 $\mathrm{L}^{\text {low }}$ and CD44 ${ }^{\text {high }} \mathrm{CD} 62 \mathrm{~L}^{\text {high }}$ markers, respectively.

microarray analyses of the CD4 $\mathrm{T}$ cell of the mice immunized $12 \times$ with OVA relative to PBS-treated mice was 0.98 for FoxP3, 1.11 for Erg-2, and 1.29 for LAG3, and thus, the finding indicates that aiCD4 $\mathrm{T}$ cell is distinct from regulatory CD4 $\mathrm{T}$ subsets. Further, while Tfh markers, B cell leukemia/ lymphoma 6 (Bcl6), inducible $\mathrm{T}$ cell costimulator (ICOS), and chemokine (C-X-C motif) receptor 5 (CXCR5), were also not significantly increased under microarray analyses, further studies should be required concerning the relationship between aiCD4 $\mathrm{T}$ cell and Tfh or exhaust T cell.

The cells that are expanded upon repeated immunization with antigen are the effector CD4 T cells uniquely expressing memory PD-1 marker. This effector CD4 T cell population would be unique in that despite expression of the PD-1 marker it shows increased production of IL-2 and IL-6 (Miyazaki et al., 2013). Production of IL-2 should normally be suppressed when PD-1 is expressed (Latchman et al., 2001; Riella et al., 2012), however, as shown by several studies, sufficiently strong signal- ing through CD28 and/or IL-2 receptor can overcome PD-1 inhibitory signaling (Nurieva et al., 2006; Bertsias et al., 2009). In fact, the PD-1-expressing CD4 $\mathrm{T}$ cell population which we found was significantly increased both in NZB/W F1 mice (Kasagi et al., 2010) and in the peripheral blood of patients with SLE (Liu et al., 2009). Since this CD4 T cells induce varieties of autoantibodies and pathological lesions identical to those seen in SLE upon transfer into naïve recipients (Tsumiyama et al., 2009), it appears that this PD-1-expressing effector CD4 T cell is an activated T cell type which has overcome PD-1 inhibition.

\section{ROLE OF B CELL: IS T CELL-CENTERED DISEASE MECHANISM VALID?}

While B cells produce autoantibodies, and intrinsic biochemical abnormalities in B cell, and T cell as well, can induce SLE, studies show that autoantibodies are produced from B cells that have undergone somatic hypermutation (SHM) with affinity maturation and class switching (Weinstein et al., 2012). Autoantibodies arise predominantly from non-autoreactive B cells that diversify immunoglobulin genes via SHM: SHM normally diversifies antibody genes during physiological responses to foreign immunogen within the microenvironment of the germinal center and thus, autoantibody-producing $\mathrm{B}$ cells are generated de novo at periphery (Guo et al., 2010; Weinstein et al., 2012). Therefore, $\mathrm{T}$ cell-centered disease mechanism seems valid in the pathogenesis of systemic autoimmunity.

\section{REFERENCES}

Bertsias, G. K., Nakou, M., Choulaki, C., Raptopoulou, A., Papadimitraki, E., Goulielmos, G., et al. (2009). Genetic, immunologic, and immunohistochemical analysis of the programmed death 1/programmed death ligand 1 pathway in human systemic lupus erythematous. Arthritis Rheum. 60, 207-218.

Duraiswamy, J., Ibegbu, C. C., Masopust, D., Miller, J. D., Araki, K., Doho, G. H., et al. (2011). Phenotype function, and gene expression profiles of programmed death- $1^{\text {hi }}$ CD8 T cells in healthy human adults. J. Immunol. 186, 4200-4212.

Francisco, L. M., Salinas, V. H., Brown, K. E., Vanguri, V. K., Freeman, G. J., Kuchroo, V. K., et al. (2009). PD-L1 regulates the development, maintenance, and function of induced regulatory T cells. J. Exp. Med. 206, 3015-3029.

Fu, S. M., Deshmukh, U. S., and Gaskin, F. (2011). Pathogenesis of systemic lupus erythematosus revisited 2011: end organ resistance to damage, autoantibody initiation and diversification, and HLA-DR. J. Autoimmun. 37, 104-112.

Guo, W., Smith, D., Aviszus, K., Detanico, T., Heiser, R. A., and Wysocki, L. J. (2010). Somatic hypermutation as a generator of antinuclear antibodies in a murine model of systemic autoimmunity. J. Exp. Med.207,2225-2237.

Haynes, N. M., Allen, C. D., Lesley, R., Ansel, K. M., Killeen, N., and Cyster, J. G. (2007). Role of CXCR5 and CCR7 in follicular Th cell positioning and appearance of a programmed cell death gene-1 high germinal center-associated subpopulation. J. Immunol. 179, 5099-5108.

Jin, H. T., Ahmed, R., and Okazaki, T. (2011). Role of PD-1 in regulating T-cell immunity. Curr. Top. Microbiol. Immunol. 350, 17-37.

Kasagi, S., Kawano, S., Okazaki, T., Honjo, T., Morinobu, A., Hatachi, S., et al. (2010). Anti-programmed cell death 1 antibody reduced $\mathrm{CD} 4^{+} \mathrm{PD}-1^{+} \mathrm{T}$ cells and relieves the lupus-like nephritis of NZB/W F1 mice. J. Immunol. 184, 2337-2347.

Latchman, Y., Wood, C. R., Chernova, T., Chaudhary, D., Borde, M., Chernova, I., et al. (2001). PD-L2 is a second ligand for PD-1 and inhibits T cell activation. Nat. Immunol. 2, 261-268.

Liu, M. F., Weng, C. T., and Weng, M. Y. (2009). Variable increased expression of program death-1 and program death-1 ligands on peripheral mononuclear cells is not impaired in patients with systemic lupus erythematosus. J. Biomed. Biotechnol. 2009, 406136.

McKinstry, K. K., Golech, S., Lee, W. H., Huston, G., Weng, N.P., and Swain, S. L. (2007). Rapid default transition of CD4 T cell effectors to functional memory cells. J. Exp. Med. 204, 2199-2211. 
Miyazaki, Y., Tsumiyama, K., Yamane, T., Ito, M., and Shiozawa, S. (2013). Expansion of PD-1-positive effector CD4 T cells in an experimental model of SLE: contribution to the self-organized criticality theory. Kobe J. Med. Sci. [Epub ahead of print].

Nurieva, R., Thomas, S., Nguyen, T., Martin-Orozco, N., Wang, Y., Kaja, M. K., et al. (2006). T-cell tolerance or function is determined by combinatorial costimulatory signals. EMBO J. 25, 2623-2633.

Perry, D., Sang, A., Yin, Y., Zheng, Y. Y., and Morel, L. (2011). Murine models of systemic lupus erythematosus. J. Biomed. Biotechnol. 2011, 271694.

Riella, L. V., Paterson, A. M., Sharpe, A. H., and Chandraker, A. (2012). Role of the PD-1 pathway in the immune response. Am. J. Transplant. 12, 2575-2587.
Shiozawa, S. (2011). Cause of systemic lupus erythematosus: a novel self-organized criticality theory of autoimmunity. Exp. Rev. Clin. Immunol. 7, 715-717.

Shiozawa, S. (2012). Pathogenesis of SLE and aiCD4 T cell: new insight on autoimmunity. Joint Bone Spine 79, 428-430.

Tsumiyama, K., Miyazaki, Y., and Shiozawa, S. (2009). Selforganized criticality theory of autoimmunity. PLoS ONE 4:e8382. doi: 10.1371/journal.pone.0008382

Wang, Y., Zhang, H. X., Sun, Y. P., Liu, Z. X., Liu, X. S., Wang, L., et al. (2007). Rig-I ${ }^{-/-}$mice develop colitis associated with down regulation of Goi2. Cell Res. 17, 858-868.

Weinstein, J. S., Hernandez, S. G., and Craft, J. (2012). $\mathrm{T}$ cells that promote B-Cell maturation in systemic autoimmunity. Immunol. Rev. 247, 160-171.
Received: 15 February 2013; accepted: 30 March 2013; published online: 10 April 2013.

Citation: Miyazaki Y, Tsumiyama K, Yamane T, Ito Mand Shiozawa S (2013) Self-organized criticality theory and the expansion of PD-1-positive effector CD4 T cells: search for autoantibody-inducing CD4 T cells. Front. Immunol. 4:87. doi: 10.3389/fimmu.2013.00087

This article was submitted to Frontiers in T Cell Biology, a specialty of Frontiers in Immunology.

Copyright (ㅇ) 2013 Miyazaki, Tsumiyama, Yamane, Ito and Shiozawa. This is an open-access article distributed under the terms of the Creative Commons Attribution License, which permits use, distribution and reproduction in other forums, provided the original authors and source are credited and subject to any copyright notices concerning any third-party graphics etc. 